\title{
Características de carcaça de codornas de corte alimentadas com diferentes níveis de proteína e energia
}

\author{
Meat quails carcass characteristics fed with different protein and energy levels
}

\author{
VASCONCELOS, Renan Costa ${ }^{1 *}$; PIRES, Aldrin Vieira ${ }^{1}$; LIMA, Heder José D’ Avila ${ }^{2}$; \\ BALLOTIN, Lucilia Maria Valadares ${ }^{1}$; VELOSO, Rogério de Carvalho ${ }^{1}$; DRUMOND, \\ Eduardo Silva Cordeiro ${ }^{1}$; GONÇALVES Flaviana Miranda ${ }^{1}$
}

\footnotetext{
${ }^{1}$ Universidade Federal dos Vales do Jequitinhonha e Mucuri, Departamento de Zootecnia, Diamantina, Minas Gerais, Brasil.

${ }^{2}$ Universidade Federal de Mato Grosso, Departamento de Zootecnia e Extensão Rural, Cuiabá, Mato Grosso, Brasil.

*Endereço para correspondência: renanvasconcelos@yahoo.com.br
}

\section{RESUMO}

Objetivou-se estudar a influência de diferentes níveis de proteína bruta e energia metabolizável sobre as características de carcaça de codornas de corte. O delineamento foi em blocos ao acaso, em esquema fatorial $(5 \times 3 \times 2)$ com cinco níveis de proteína bruta (PB) $(18 ; 20 ; 22 ; 24$ e $26 \%$ ), três níveis de energia metabolizável (EM) (2700; 2900 e $3100 \mathrm{Kcal} \mathrm{EM} / \mathrm{Kg}$ ) e dois sexos, com três repetições. As codornas foram criadas em gaiolas experimentais durante todo 0 período, sendo a ração fornecida à vontade. Duas aves de cada sexo, por unidade experimental, foram abatidas aos 50 dias, após jejum de 10 horas, para avaliação das características de peso: corporal ao abate, carcaça, peito, pernas, asa, fígado, moela e coração. Os modelos de regressão múltipla foram adotados como método de análise estatística. Não foi verificado efeito significativo $(\mathrm{P}>0,05)$ dos níveis de $\mathrm{PB}$ estudados sobre as características de carcaça, corte ou peso de vísceras, das codornas de corte de ambos os sexos, exceto para peso do coração. Maiores valores de características de carcaça de codornas de corte, machos e fêmeas da linhagem fêmea 2 (LF2) são obtidas com ração formulada com 18\% PB e $2700 \mathrm{kcal} \mathrm{EM} / \mathrm{kg}$.

Palavras-chave: Coturnix coturnix, nutrição, peso corporal, rendimento

\section{SUMMARY}

The study was conducted to evaluate the influence of different levels of crude protein and metabolizable energy on carcass characteristics of quails. The experimental design was randomized blocks, factorial $(5 \times 3 \times 2)$ with five levels of crude protein (PB) $(18 ; 20 ; 22 ; 24$ and $26 \%$ ), three levels of metabolizable energy (EM) (2700; 2900 and 3100 scheme kcal / kg) and both sexes, with three replications. The quail were reared in cages throughout the experimental period, being the feed provided ad libitum. Two birds of each sex per experimental unit, were slaughtered at 50 days, after fasting for 10 hours, to evaluate of weight: body slaughter, carcass, breast, legs, wings, liver, gizzard and heart. The multiple regression models were adopted as a method of statistical analysis. There was no significant effect of PB levels studied on carcass traits, cut or weight of viscera, the quails of both sexes, except for heart weight. The best carcass characteristics of quails, males and females of the female lineage 2 (LF2) are obtained with ration with $18 \% \mathrm{CP}$ and $2700 \mathrm{kcal} / \mathrm{kg}$.

Keywords: Coturnix coturnix, nutrition, body weight, yield 


\section{INTRODUÇÃO}

No Brasil, as codornas foram introduzidas para produção de ovos (Coturnix japonica), que eram, ao final do ciclo de postura, destinadas ao abate. Porém, as aves apresentavam baixo peso corporal e carcaças de má qualidade. Com a crescente demanda pela carne de codorna no mercado, recentemente, foi introduzida no país a linhagem de codornas europeias (Coturnix coturnix) especializada na produção de carne (MÓRI et al., 2005), também chamadas de codornas de corte. As codornas possuem maturidade sexual precoce (35 a 40 dias de idade), necessitando de uma dieta que maximize a taxa de crescimento e o peso final da ave para início da produção de ovos ou abate (LIMA et al., 2011). A conformação de carcaça precisa ser melhorada, devido ao baixo rendimento de cortes nobres.

No entanto, as exigências nutricionais das codornas de corte são bastante diferentes das linhagens de postura e, ainda, há poucos estudos sobre estas exigências para as condições brasileiras. Também, faz-se necessário aumentar o peso de carcaça e de cortes nobres. Assim, estudos principalmente sobre proteína bruta e energia metabolizável tornam-se relevantes, pois são os componentes da dieta com maior custo e, em níveis não adequados, podem comprometer o desempenho produtivo das codornas.

Objetivou-se avaliar os efeitos de diferentes níveis de proteína bruta e energia metabolizável da ração sobre o rendimento de carcaça e cortes, peso vivo, peso de carcaça, peso de cortes nobres e peso de vísceras comestíveis, de codornas de corte de ambos os sexos.

\section{MATERIAL E MÉTODOS}

O experimento foi conduzido nas instalações do Programa de Melhoramento Genético de Codornas da Universidade Federal dos Vales do Jequitinhonha e Mucuri, Diamantina MG, utilizando a linhagem fêmea 2 (LF2) de codorna europeia (Coturnix coturnix). As aves com 1 dia de idade foram alojadas em bateria, confeccionada em arame galvanizado, contendo comedouros, bebedouros e bandeja coletora de excretas. O sistema de aquecimento foi constituído por lâmpadas infravermelho de 250 watts e proporcionou aquecimento até o $28^{\circ}$ dia de idade. As codornas receberam água e ração à vontade durante todo o período experimental.

O experimento foi realizado com 540 codornas europeias distribuídas em delineamento em blocos casualizado, sendo os blocos constituídos pela posição das gaiolas no interior do galpão, em esquema fatorial $5 \times 3 \times 2$, cinco níveis de proteína bruta $(\mathrm{PB})(18 ; 20 ; 22 ; 24$ e $26 \%$ ), três níveis de energia metabolizável (EM) (2700; 2900 e 3100 $\mathrm{Kcal} / \mathrm{kg}$ ) e dois sexos, com três repetições de 12 aves cada. Cada gaiola possuía dimensão de 50 × $35 \times 20 \mathrm{~cm}$, contendo $50 \%$ de machos e $50 \%$ de fêmeas.

As dietas experimentais (Tabela 1) foram formuladas à base de milho e farelo de soja, conforme informações de composições e digestibilidade dos ingredientes contidas nas recomendações de Rostagno et al. (2005) e exigências nutricionais de acordo com o NRC (1994).

No $50^{\circ}$ dia foram retiradas ao acaso e abatidas duas codornas de cada sexo, de cada unidade experimental, totalizando 180 codornas. Após jejum alimentar de 10 horas, as aves foram pesadas individualmente e identificadas com uma etiqueta na pata esquerda. 
Rev. Bras. Saúde Prod. Anim., Salvador, v.15, n.4, p.1017-1026 out./dez., 2014 http://www.rbspa.ufba.br ISSN 15199940

Tabela 1. Composições percentuais e calculadas das rações para codornas de corte

\begin{tabular}{|c|c|c|c|c|c|}
\hline \multicolumn{6}{|c|}{ Energia Metabolizável - 2700 kcal/kg } \\
\hline \multirow{2}{*}{ Ingredientes } & \multicolumn{5}{|c|}{ Proteína Bruta (\%) } \\
\hline & 18 & 20 & 22 & 24 & 26 \\
\hline Milho Grão & 65,219 & 60,551 & 56,065 & 51,727 & 47,687 \\
\hline Farelo de Soja (45\%) & 29,553 & 34,352 & 38,991 & 43,478 & 47,977 \\
\hline L-Lysina - HCl (78\%) & 0,505 & 0,328 & 0,150 & 0,000 & 0,000 \\
\hline DL-Metionina (98\%) & 0,232 & 0,200 & 0,168 & 0,138 & 0,108 \\
\hline Fosfato Bicálcico & 1,719 & 1,65 & 1,584 & 1,520 & 0,923 \\
\hline Calcário Calcítico & 1,923 & 1,874 & 1,827 & 1,781 & 1,955 \\
\hline Sal comum & 0,349 & 0,349 & 0,350 & 0,349 & 0,350 \\
\hline Mistura vitamínica e mineral $^{1}$ & 0,500 & 0,500 & 0,500 & 0,500 & 0,500 \\
\hline Areia lavada ${ }^{2}$ & 0,000 & 0,196 & 0,365 & 0,507 & 0,500 \\
\hline Total & 100,00 & 100,00 & 100,00 & 100,00 & 100,00 \\
\hline \multicolumn{6}{|c|}{ Energia Metabolizável - $2900 \mathrm{kcal} / \mathrm{kg}$} \\
\hline \multirow{2}{*}{ Ingredientes } & \multicolumn{5}{|c|}{ Proteína Bruta (\%) } \\
\hline & 18 & 20 & 22 & 24 & 26 \\
\hline Milho Grão & 68,336 & 64,566 & 59,201 & 52,615 & 45,861 \\
\hline Farelo de Soja $(45 \%)$ & 26,63 & 31,523 & 36,927 & 42,623 & 48,32 \\
\hline L-Lysina - HCl $(78 \%)$ & 0,530 & 0,352 & 0,168 & 0,000 & 0,000 \\
\hline DL-Metionina (98\%) & 0,216 & 0,187 & 0,161 & 0,135 & 0,109 \\
\hline Fosfato Bicálcico & 1,607 & 1,019 & 0,986 & 0,956 & 0,927 \\
\hline Calcário Calcítico & 1,832 & 1,355 & 1,093 & 1,069 & 1,046 \\
\hline Óleo de Soja & 0,000 & 0,000 & 0,615 & 1,751 & 2,887 \\
\hline Sal comum & 0,349 & 0,350 & 0,349 & 0,351 & 0,350 \\
\hline Mistura vitamínica e mineral $^{1}$ & 0,500 & 0,500 & 0,500 & 0,500 & 0,500 \\
\hline Areia lavada ${ }^{2}$ & 0,000 & 0,148 & 0,000 & 0,000 & 0,000 \\
\hline Total & 100,00 & 100,00 & 100,00 & 100,00 & 100,00 \\
\hline \multicolumn{6}{|c|}{ Energia Metabolizável - 3100 kcal/kg } \\
\hline \multirow{2}{*}{ Ingredientes } & \multicolumn{5}{|c|}{ Proteína Bruta (\%) } \\
\hline & 18 & 20 & 22 & 24 & 26 \\
\hline Milho Grão & 67,577 & 61,012 & 54,449 & 47,845 & 41,091 \\
\hline Farelo de Soja (45\%) & 26,429 & 32,125 & 37,822 & 43,518 & 49,215 \\
\hline L-Lysina - HCl (78\%) & 0,531 & 0,341 & 0,150 & 0,000 & 0,000 \\
\hline DL-Metionina(98\%) & 0,215 & 0,189 & 0,163 & 0,137 & 0,111 \\
\hline Fosfato Bicálcico & 1,056 & 1,026 & 0,997 & 0,968 & 0,938 \\
\hline Calcário Calcítico & 1,128 & 1,105 & 1,082 & 1,058 & 1,035 \\
\hline Óleo de Soja & 2,215 & 3,351 & 4,487 & 5,623 & 6,760 \\
\hline Sal comum & 0,349 & 0,351 & 0,350 & 0,351 & 0,350 \\
\hline Mistura vitamínica e mineral $^{1}$ & 0,500 & 0,500 & 0,500 & 0,500 & 0,500 \\
\hline Total & 100,00 & 100,00 & 100,00 & 100,00 & 100,00 \\
\hline \multicolumn{6}{|c|}{ Composição química calculada } \\
\hline Lisina digestível (\%) & 1,3 & 1,3 & 1,3 & 1,3 & 1,3 \\
\hline Metionina digestível (\%) & 0,5 & 0,5 & 0,5 & 0,5 & 0,5 \\
\hline Metionina + Cistina dig $(\%)$ & 0,75 & 0,75 & 0,75 & 0,75 & 0,75 \\
\hline Cálcio $(\%)$ & 0,8 & 0,8 & 0,8 & 0,8 & 0,8 \\
\hline Fósforo disponível (\%) & 0,3 & 0,3 & 0,3 & 0,3 & 0,3 \\
\hline Sódio $(\%)$ & 0,15 & 0,15 & 0,15 & 0,15 & 0,15 \\
\hline \multicolumn{6}{|c|}{$\begin{array}{l}{ }^{\mathrm{T}} \text { Suplemento vitamínico e mineral por kg do produto, vit. A } 3.750 .000 \mathrm{UI} \text {; vit. } \mathrm{D}_{3}, 750.000 \mathrm{UI} \text {; vit. E } \\
7500 \mathrm{mg} \text {; vit } \mathrm{K}_{3}, 1.000 \mathrm{mg} \text {; vit. } \mathrm{B}_{1}, 750 \mathrm{mg} \text {; vit. } \mathrm{B}_{2}, 1.500 \mathrm{mg} \text {; vit. } \mathrm{B}_{6}, 1500 \mathrm{mg} \text {; vit. } \mathrm{B}_{12}, 7.500 \mathrm{mcg} \text {; vit. } \\
\mathrm{C} 12.500 \mathrm{mg} \text {, biotina } 30 \mathrm{mg} \text {, niacina } 10.000 \mathrm{mg} \text {, ácido fólico } 375 \text {; acido pantotênico } 3.750 \mathrm{mg} \text {; colina } \\
10.000 \mathrm{mg} \text {, metionina } 400.000 \mathrm{mg} \text {, selênio } 45 \mathrm{mg} \text {; iodo } 175 \mathrm{mg} \text {; ferro } 12.525 \mathrm{mg} \text {; cobre } 2.500 \mathrm{mg} \text {; } \\
\text { manganês, } 19.500 \mathrm{mg} \text {; zinco } 13.750 \mathrm{mg} \text {; prom. Prod } 15.000 \mathrm{mg} \text {, coccidiostático } 10.000 \mathrm{mg} \text {, antioxidante } \\
\text { (B.H.T) } 500 \mathrm{mg} \text {. } \\
\text { 2Inerte. }\end{array}$} \\
\hline
\end{tabular}


Rev. Bras. Saúde Prod. Anim., Salvador, v.15, n.4, p.1017-1026 out./dez., 2014 http://www.rbspa.ufba.br ISSN 15199940

Foi procedida a insensibilização pela secção da medula espinhal, seguida por sangria com espera por dois minutos, para a realização da escalda, sendo a depena realizada manualmente. As carcaças, evisceradas e desprovidas de patas e cabeça, foram lavadas e pesadas, em seguida foram realizados os cortes para obtenção do peso e rendimento de carcaça, Foram avaliadas as seguintes características: peso corporal (PC), peso de carcaça (PCA), peso de peito (PP), peso de pernas (PPE), peso de asa (PA), peso de fígado $(\mathrm{PF})$, peso de moela $(\mathrm{PM})$ e peso de coração (PCO), além de rendimento de carcaça (RCA), rendimento de peito (RP) e rendimento de pernas (RPE). Os rendimentos de peito e pernas foram obtidos com relação ao peso da carcaça.

As análises estatísticas foram realizadas por meio da metodologia de regressão múltipla, utilizando-se os procedimentos GLM e REG do programa SAS (SAS Institute, 1990).

\section{RESULTADOS E DISCUSSÃO}

Não houve interação entre EMxPB para nenhuma das características avaliadas. Não foi observado efeito significativo $(\mathrm{P} \geq 0,05)$ da $\mathrm{EM}, \mathrm{PB}$ ou da interação entre esses e sexo em relação ao peso da carcaça (Tabela 2). Os diferentes níveis de proteína e energia nas dietas não interferiram nas características de carcaça de codornas de corte. Ainda que a variação no teor de proteína bruta tenha sido elevada, de 18 a $26 \%$, a manutenção dos requerimentos nutricionais de aminoácidos essenciais como lisina e metionina, em níveis e relações que atendem à exigência da espécie pode ter corroborado para $\mathrm{o}$ crescimento e ganho em peso das aves independente do nível protéico. Neste sentido, a presente pesquisa pode servir como referencial de redução do nível protéico para estudos com base na proteína ideal.

Tabela 2. Peso corporal (PC), peso da carcaça (PCA) e rendimento da carcaça (RCA) de codornas de corte aos 50 dias de idade em função dos níveis de EM e PB da ração

\begin{tabular}{|c|c|c|c|c|c|c|c|c|c|}
\hline & \multicolumn{9}{|c|}{ Probabilidade } \\
\hline Característica & \multicolumn{3}{|c|}{$\mathrm{PC}(\mathrm{g})$} & \multicolumn{3}{|c|}{ PCA $(g)$} & \multicolumn{3}{|c|}{$\mathrm{RCA}(\%)$} \\
\hline PB & \multicolumn{3}{|c|}{0,6532} & \multicolumn{3}{|c|}{0,3091} & \multicolumn{3}{|c|}{0,1055} \\
\hline EM & \multicolumn{3}{|c|}{0,3746} & \multicolumn{3}{|c|}{0,9951} & \multicolumn{3}{|c|}{0,2208} \\
\hline Sexo & \multicolumn{3}{|c|}{0,0001} & \multicolumn{3}{|c|}{0,0701} & \multicolumn{3}{|c|}{0,0001} \\
\hline Interação & \multicolumn{3}{|c|}{ EMxSexo } & \multicolumn{3}{|c|}{ NS } & \multicolumn{3}{|c|}{ NS } \\
\hline & \multicolumn{9}{|c|}{ Proteína Bruta $(\%)$} \\
\hline Sexo & Macho & Fêmea & Média & Macho & Fêmea & Media & Macho & Fêmea & Média \\
\hline 18 & 250,4 & 258,5 & 254,4 & 179,7 & 180,5 & 180,1 & 71,7 & 69,9 & 70,8 \\
\hline 20 & 243,8 & 262,9 & 253,4 & 176 & 180,1 & 178 & 72,2 & 68,6 & 70,4 \\
\hline 22 & 227,8 & 269,8 & 248,8 & 162,5 & 180,8 & 171,7 & 71,4 & 67,2 & 69,3 \\
\hline 24 & 246,7 & 252,9 & 249,8 & 176,7 & 176,5 & 176,6 & 71,7 & 70,3 & 71 \\
\hline \multirow[t]{2}{*}{26} & 250,2 & 270,4 & 260,3 & 184,9 & 180,7 & 182,8 & 73,9 & 69,8 & 71,9 \\
\hline & \multicolumn{9}{|c|}{ Energia Met. (kcal EM/kg) } \\
\hline 2700 & $237,8^{\mathrm{B}}$ & $269,4^{\mathrm{A}}$ & 253,6 & 171,7 & 183,8 & 177,8 & 72,2 & 68,3 & 70,3 \\
\hline 2900 & $249,3^{\mathrm{B}}$ & $266,4^{\mathrm{A}}$ & 257,8 & 179,3 & 181,9 & 180,6 & 71,9 & 68,4 & 70,1 \\
\hline 3100 & $244,2^{\mathrm{B}}$ & $252,6^{\mathrm{A}}$ & 248,4 & 176,8 & 178,3 & 177,6 & 72,4 & 70,8 & 71,6 \\
\hline Média & 243,8 & 262,8 & 253,3 & 176 & 181,3 & 178,7 & $72,2^{\mathrm{A}}$ & $69,1^{\mathrm{B}}$ & 70,7 \\
\hline $\mathrm{CV}(\%)$ & & 8,62 & & & 8,26 & & & 4,47 & \\
\hline
\end{tabular}

Médias na linha, seguidas por letras diferentes, diferem pelo teste $\mathrm{F}(\mathrm{P}<0,05)$, dentro da mesma característica. 
Para o peso corporal (PC) houve interação significativa entre EM e sexo. Corrêa et al. (2007a) não encontraram efeito dos níveis de PB e EM sobre o peso corporal de codornas de corte. Por outro lado, Corrêa et al. (2007b) verificaram que codornas fêmeas apresentaram maiores peso corporal, peso do peito, além do peso e rendimento de fígado e peso de moela em relação aos machos, independente dos níveis nutricionais administrados, sendo que os machos apresentaram maior rendimento de carcaça, o que corrobora com os resultados deste trabalho. Em função da idade de abate, esses dados são justificados pelo ganho em peso dos órgãos relacionados à maturidade sexual nas fêmeas.

O desdobramento do efeito de sexo dentro de EM (Tabela 2) demonstrou que codornas fêmeas apresentaram maior PC e menor RCA, em relação aos machos, para todos os níveis de EM estudados. Este comportamento é devido ao maior peso do trato reprodutivo e maior deposição de gordura nas fêmeas, o que resulta em maior peso corporal, mas não em rendimento de carcaça (OLIVEIRA, 2005). Resultados similares foram observados por outros autores, Oliveira et al. (2002) verificaram efeito significativo do sexo sobre o peso corporal em todas as idades, sendo as fêmeas mais pesadas. Silva et al. (2007) constataram que codornas fêmeas apresentaram maior peso vivo em seis planos nutricionais em comparação aos machos.

Os resultados correspondentes aos níveis de energia das dietas, possivelmente, estão relacionados com a regulação da ingestão alimentar pelas aves e com a ampla fase de estudo, ou seja, dados de características de carcaça relativos aos tratamentos para o período de 1 a 50 dias de idade.
A idade de abate, no presente estudo aos 50 dias, pode influenciar na exigência energética das codornas, visto que nessa idade elas estão em fase reprodutiva, na qual necessita de menos energia metabólica do que na fase de crescimento (BARRETO et al., 2007).

Verificou-se efeito linear decrescente $(\mathrm{P} \leq 0,05)$ da EM sobre $\mathrm{PC}(\mathrm{PC}=392,76-$ $\left.0,0448 \mathrm{EM} ; \mathrm{R}^{2}=0,98\right)$ para fêmeas, sendo estimado $2700 \mathrm{kcal} \mathrm{EM} / \mathrm{kg}$ para maior PC (Tabela 2). Corrêa (2007a) verificou interação significativa entre sexo e energia metabolizável da dieta, em que os machos apresentaram maior peso corporal, peso de carcaça, peito e fígado, quando alimentados com dietas contendo $3100 \mathrm{kcal} \mathrm{EM} / \mathrm{kg}$, e para as fêmeas alimentadas com dietas contendo $2900 \mathrm{kcal} \mathrm{EM} / \mathrm{kg}$. Drumond (2010) constatou maior peso médio da carcaça quando se utilizaram rações com $24 \%$ PB e $3100 \mathrm{kcal} \mathrm{EM/kg}$.

Não houve interação entre PBxSexo ou EMxSexo, nem efeito de PB ou EM sobre o rendimento da carcaça (RCA). Verificou-se somente efeito de sexo sobre RCA (Tabela 2), onde se constatou que os machos, embora tenham apresentado menor peso corporal, apresentaram maior RCA $(72,17 \%)$ enquanto as fêmeas apresentaram RCA de 69,14\%. Este resultado se justifica devido às retiradas de ovário e oviduto durante a evisceração, além da maior deposição de gordura abdominal nas fêmeas. Dados semelhantes foram descritos por Oliveira et al. (2002), em que o peso vivo das fêmeas foi superior ao dos machos, mas o rendimento de carcaça foi inferior.

Houve interação $(\mathrm{P} \leq 0,05)$ entre $\mathrm{EM}$ e sexo para peso das pernas (PPE) (Tabela 3). Não houve efeito significativo $(\mathrm{P}>0,05)$ da EM ou $\mathrm{PB}$ em relação ao peso do peito (PP), peso da asa (PA), rendimento do peito (RP) e rendimento das pernas (RPE). 
O sexo influenciou significativamente $(\mathrm{P} \leq 0,05)$ o PP, PPE e RP.

As codornas fêmeas apresentaram maior peso $(76,48 \mathrm{~g})$ e rendimento de peito $(42,17 \%)$ do que os machos $(72,42 \mathrm{~g} \mathrm{e}$ $41,14 \%$, respectivamente). Silva et al. (2007) ao alimentarem codornas, machos e fêmeas, com quatro planos nutricionais, constataram maior peso do peito de codornas fêmeas comparado ao dos machos, entretanto não houve diferença entre machos e fêmeas para o rendimento de peito.

Ton et al. (2011) e Correa et al. (2007b) não constataram efeito significativo para EM em relação ao peso e rendimento do peito em codornas de corte na fase de crescimento. Móri et al. (2005) não verificaram diferença para rendimento de peito em diferentes grupos genéticos, com rendimento médio de $35,32 \%$. Resultado que difere do presente estudo é apresentado por Otutumi et al. (2009), no qual observaram que a $\mathrm{PB}$ promoveu efeito cubico para rendimento de peito, resultando na exigência de 26,47\%-

Silva et al. (2007) observaram que os tratamentos que resultaram em pior consumo de ração e ganho de peso, promoveram melhor rendimento de pernas, pressupondo que $\mathrm{o}$ desenvolvimento desta variável é menos influenciado pela redução do nível de proteína e da qualidade da dieta.

Analisando os resultados do peso de pernas (PPE), verificou-se ajuste pelo modelo linear ( $\mathrm{PPE}=59,461$ $\left.0,0063 \mathrm{EM} ; \quad \mathrm{R}^{2}=0,90\right) \quad(\mathrm{P} \leq 0,05) \quad$ dos níveis de energia metabolizável para fêmeas (Tabela 3). Observou-se PPE maior com $2900 \mathrm{kcal} \mathrm{EM} / \mathrm{kg}$ para fêmeas. Ainda que tenha sido verificado maior peso para essa variável, a variação foi somente $1,18 \%$ maior que o PPE das codornas alimentadas com $2700 \mathrm{kcal} \mathrm{EM} / \mathrm{kg}$. Por outro lado, Drumond (2010) verificou maior peso de pernas em dieta com 3100 kcal $\mathrm{EM} / \mathrm{kg}$.

Tabela 3. Peso do peito (PP), rendimento do peito (RP), peso das pernas (PPE) de codornas de corte aos 50 dias de idade em função dos níveis de EM e PB da ração

\begin{tabular}{|c|c|c|c|c|c|c|c|c|c|c|}
\hline & \multicolumn{10}{|c|}{ Probabilidade } \\
\hline Característica & \multicolumn{2}{|c|}{$\mathrm{PP}(\mathrm{g})$} & \multicolumn{2}{|c|}{$\mathrm{RP}(\%)$} & \multicolumn{2}{|c|}{ PPE $(g)$} & \multicolumn{2}{|c|}{ RPE (\%) } & \multicolumn{2}{|c|}{$\mathrm{PA}(\%)$} \\
\hline $\mathrm{PB}$ & \multicolumn{2}{|c|}{0,2165} & \multicolumn{2}{|c|}{0,5153} & \multicolumn{2}{|c|}{0,6214} & \multicolumn{2}{|c|}{0,7835} & \multicolumn{2}{|c|}{0,157} \\
\hline EM & \multicolumn{2}{|c|}{0,78} & \multicolumn{2}{|c|}{0,6798} & \multicolumn{2}{|c|}{0,3997} & \multicolumn{2}{|c|}{0,3988} & \multicolumn{2}{|c|}{0,3202} \\
\hline Sexo & \multicolumn{2}{|c|}{0,0096} & \multicolumn{2}{|c|}{0,0311} & \multicolumn{2}{|c|}{0,026} & \multicolumn{2}{|c|}{0,7835} & \multicolumn{2}{|c|}{0,8512} \\
\hline Interação & \multicolumn{2}{|c|}{ NS } & \multicolumn{2}{|c|}{ NS } & \multicolumn{2}{|c|}{ EMxSexo } & \multicolumn{2}{|c|}{ NS } & \multicolumn{2}{|c|}{ NS } \\
\hline & \multicolumn{10}{|c|}{ Proteína Bruta $(\%)$} \\
\hline Sexo & Macho & Fêmea & Macho & Fêmea & Macho & Fêmea & Macho & Fêmea & Macho & Fêmea \\
\hline 18 & 73,5 & 75,2 & 40,9 & 41,6 & 40,9 & 41,2 & 22,8 & 22,8 & 14,7 & 14,1 \\
\hline 20 & 72,2 & 76,2 & 41 & 42,3 & 40 & 40,6 & 22,8 & 22,6 & 14,1 & 14 \\
\hline 22 & 66,2 & 78,1 & 40,7 & 43,2 & 37,5 & 40,3 & 23,1 & 22,3 & 13,6 & 13,7 \\
\hline 24 & 72,6 & 72,2 & 41,1 & 40,9 & 39 & 41 & 22,1 & 23,2 & 13,9 & 14 \\
\hline \multirow[t]{2}{*}{26} & 77,6 & 80,7 & 42 & 42,7 & 41 & 43 & 22,2 & 22,8 & 13,2 & 14,3 \\
\hline & \multicolumn{10}{|c|}{ Energia Met. (kcal EM/kg) } \\
\hline 2700 & 71,7 & 77,4 & 41,7 & 42,1 & $39,0^{\mathrm{B}}$ & $41,9^{\mathrm{A}}$ & 22,7 & 22,8 & 13,4 & 14 \\
\hline 2900 & 73,2 & 76,9 & 40,8 & 42,3 & $40,2^{\mathrm{B}}$ & $42,4^{\mathrm{A}}$ & 22,4 & 23,3 & 14 & 14,3 \\
\hline 3100 & 72,4 & 75,2 & 41 & 42,1 & $39,9^{\mathrm{B}}$ & $39,4^{\mathrm{A}}$ & 22,6 & 22,1 & 14,3 & 13,8 \\
\hline Média & $72,4^{\mathrm{B}}$ & $76,5^{\mathrm{A}}$ & $41,1^{\mathrm{B}}$ & $42,2^{\mathrm{A}}$ & 39,7 & 41,2 & 22,6 & 22,7 & 13,9 & 14 \\
\hline $\mathrm{CV}(\%)$ & \multicolumn{2}{|c|}{10,54} & \multicolumn{2}{|c|}{5,63} & \multicolumn{2}{|c|}{7,86} & \multicolumn{2}{|c|}{6,42} & \multicolumn{2}{|c|}{10,65} \\
\hline
\end{tabular}

Médias na linha, seguidas por letras diferentes, diferem pelo teste $\mathrm{F}(\mathrm{P}<0,05)$, dentro da mesma característica. 
Corrêa et al. (2007b) encontraram efeito quadrático da $\mathrm{PB}$ sobre o rendimento de pernas com dietas de $2900 \mathrm{kcal} \mathrm{EM} / \mathrm{kg}$ para os machos, que apresentaram máximo rendimento com $24,28 \%$ de $\mathrm{PB}$, enquanto para as fêmeas, não foi verificado efeito dos níveis de PB.

Estimativa de alta correlação genética entre peso de carcaça e peso de pernas foi encontrada por Winter (2005), indicando que o aumento do peso de carcaça pode proporcionar maior peso de pernas, e que um acréscimo do peso de peito também deverá resultar em aumento no peso de pernas.

Não se verificou efeito significativo $(\mathrm{P}>0,05)$ da $\mathrm{PB}$, da $\mathrm{EM}$ ou da interação dessas fontes de variação com o sexo para o peso da moela (PM). Houve efeito $(\mathrm{P} \leq 0,05)$ isolado do sexo sobre essa variável, sendo que as codornas fêmeas apresentaram maior PM $(5,74 \mathrm{~g})$ em comparação com os machos $(5,21 \mathrm{~g})$ (Tabela 4). Winter (2005) constatou que com a seleção para peso corporal o peso da moela foi pouco alterado.

Tabela 4. Peso da moela (PM), peso do fígado (PF) e peso do coração (PCO) de codornas de corte aos 50 dias de idade em função dos níveis de EM e PB da ração

\begin{tabular}{|c|c|c|c|c|c|c|c|c|c|}
\hline & \multicolumn{9}{|c|}{ Probabilidade } \\
\hline Característica & \multicolumn{3}{|c|}{ PM (g) } & \multicolumn{3}{|c|}{$\mathrm{PF}(\%)$} & \multicolumn{3}{|c|}{$\mathrm{PCO}(\mathrm{g})$} \\
\hline PB & \multicolumn{3}{|c|}{0,6479} & \multicolumn{3}{|c|}{0,071} & \multicolumn{3}{|c|}{0,0078} \\
\hline EM & \multicolumn{3}{|c|}{0,7706} & \multicolumn{3}{|c|}{0,4407} & \multicolumn{3}{|c|}{0,0097} \\
\hline Sexo & \multicolumn{3}{|c|}{0,0001} & \multicolumn{3}{|c|}{0,0001} & \multicolumn{3}{|c|}{0,0278} \\
\hline Interação & \multicolumn{3}{|c|}{ NS } & \multicolumn{3}{|c|}{ NS } & \multicolumn{3}{|c|}{ PB x EM x Sexo } \\
\hline & \multicolumn{9}{|c|}{ Proteína Bruta $(\%)$} \\
\hline Sexo & Macho & Fêmea & Média & Macho & Fêmea & Media & Macho & Fêmea & Média \\
\hline 18 & 5,6 & 5,8 & 5,7 & 4,6 & 5 & 4,8 & 2,8 & 2,1 & 2,4 \\
\hline 20 & 5 & 5,6 & 5,3 & 3,9 & 5 & 4,5 & 2,1 & 2,0 & 2,1 \\
\hline 22 & 5 & 5,7 & 5,4 & 4,6 & 5,1 & 4,8 & 2,1 & 2,2 & 2,1 \\
\hline 24 & 5,2 & 5,7 & 5,4 & 4 & 4,8 & 4,4 & 2,1 & 2,1 & 2,1 \\
\hline \multirow[t]{2}{*}{26} & 5,2 & 5,1 & 5,2 & 4 & 4,6 & 4,3 & 2,2 & 2,4 & 2,3 \\
\hline & \multicolumn{9}{|c|}{ Energia Met. (kcal EM/kg) } \\
\hline 2700 & 5,1 & 5,8 & 5,4 & $3,9^{\mathrm{B}}$ & $4,9^{\mathrm{A}}$ & 4,4 & 2,3 & 2,2 & 2,2 \\
\hline 2900 & 5,4 & 5,9 & 5,7 & $4,3^{\mathrm{B}}$ & $5,0^{\mathrm{A}}$ & 4,6 & 2,3 & 2,2 & 2,3 \\
\hline 3100 & 5,2 & 5,5 & 5,3 & $4,5^{\mathrm{B}}$ & $4,7^{\mathrm{A}}$ & 4,6 & 2,1 & 2,1 & 2,1 \\
\hline Média & $5,2^{\mathrm{B}}$ & $5,7^{\mathrm{A}}$ & 5,5 & 4,2 & 4,9 & 4,6 & 2,3 & 2,2 & 2,2 \\
\hline $\mathrm{CV}(\%)$ & & 11,3 & & & 16,27 & & & 27,49 & \\
\hline
\end{tabular}

As codornas fêmeas apresentaram maior peso do fígado $(\mathrm{PF}=0,2489+$ $\left.0,0015 \mathrm{EM} ; \mathrm{R}^{2}=0,75\right)$, o que pode ser explicado pela possível maturação do aparelho reprodutor e aumento da atividade em órgãos correlacionados, onde há grande depósito de gordura para o início da atividade reprodutiva (LIMA et al., 2011). Oliveira et al. (2005), observaram superioridade das fêmeas em relação aos machos para rendimento de vísceras comestíveis apenas no nível de $22 \%$ PB, constatando, portanto, interação sexo $\mathrm{x}$ proteína.

De acordo com Rezende et al. (2004), aves que receberam dieta com menor nível proteico apresentaram o fígado mais pesado, sendo que aos 14 dias houve diferença significativa para aves alimentadas com dieta contendo 2900 $\mathrm{kcal} \mathrm{EM} / \mathrm{kg}$. Por outro lado, Oliveira et 
al. (2002) não verificou efeito significativo da proteína da ração sobre o rendimento de vísceras comestíveis (coração, fígado e moela) em codornas aos 49 dias de idade. Resultados esses semelhantes aos do presente estudo, exceto para peso do coração (PCO), em que houve interação $(\mathrm{P} \leq 0,05)$ entre $\mathrm{EM}$, PB e sexo.

O maior peso de coração foi verificado para as codornas macho em dietas contendo $18 \%$ de PB e $2700 \mathrm{kcal}$ $\mathrm{EM} / \mathrm{kg}$. Winter (2005) observou que o peso do coração pode ser aumentado com a seleção para peso corporal às quatro semanas de idade, porém, o peso da moela será pouco alterado, além de ter constatado correlação genética negativa entre o peso do coração e porcentagem de gordura abdominal.

Ao contrário dos machos, as fêmeas apresentaram maior peso do coração quando receberam dieta com nível proteico mais alto (26\%). Resultado diferente do presente estudo foi apresentado por Corrêa (2010), que não encontrou diferença significativa para peso do coração em dietas com diferentes níveis proteicos em rações para codornas de corte (linhagem EV1), porém observou-se que houve efeito significativo do nível de proteína da dieta sobre o peso do coração na linhagem EV2, com o máximo peso de coração ao utilizar 30,07\% PB na ração. Não foi verificado efeito significativo $(\mathrm{P}>0,05)$ dos níveis de $\mathrm{PB}$ estudados sobre as características de carcaça, cortes ou peso de vísceras, das codornas de corte de ambos os sexos, exceto para peso do coração. Valores maiores para os níveis de proteína e energia encontrados na literatura devem-se às diferenças genéticas e fase de estudo avaliadas, considerando que o abate das codornas tem sido efetuado com variações de 35 a 50 dias de idade. $\mathrm{O}$ uso de $2700 \mathrm{kcal} \mathrm{EM} / \mathrm{kg}$ e $18 \% \mathrm{~PB}$ na dieta proporcionou peso do peito, corte mais nobre e, de vísceras comestíveis como fígado e moela similar à utilização de níveis nutricionais mais elevados. O nível de energia de 2900 $\mathrm{kcal} / \mathrm{kg}$ e $26 \%$ de proteína bruta proporcionou maior peso de pernas e de coração respectivamente para codornas fêmeas. Contudo, recomenda-se dieta contendo $2700 \mathrm{kcal} \mathrm{EM} / \mathrm{kg}$ e $18 \% \mathrm{~PB}$ para codornas fêmea e macho da linhagem fêmea 2 (LF2) de 1 a 50 dias de idade, por serem estes níveis os que apresentaram melhores resultados quanto às características de carcaça.

\section{REFERÊNCIAS}

BARRETO, S.L.T.; QUIRINO, B.J.S.; BRITO, C.O.; UMIGI, R.T.; ARAUJO, M.S.; COIMBRA, J.S.R.; ROJAS, E.E.G.; FREITAS, J.F.; REIS, R.S. Níveis de energia metabolizável para codornas japonesas na fase inicial de postura. Revista Brasileira de Zootecnia, v.36, n.1, p.79-85, 2007.

CORRÊA, G. S. S.; SILVA, M A.; CORRÊA, A. B.; ALMEIDA, V.; FONTES, D.O.; TORRES, R.A.; DIONELLO, N.J.L. Exigências de proteína bruta e energia metabolizável em codornas de corte durante a fase de crescimento. Arquivo Brasileiro de Medicina Veterinária e Zootecnia, v.59, n.2, p.488-494, 2007a.

CORRÊA, G.S.S.; SILVA, M.A.; CORRÊA, A.B.; FONTES, D.O.; TORRES, R.A.; DIONELLO, N.J.L.; SANTOS, G.G.; FREITAS, L.S. Exigência de proteína bruta e energia metabolizável para codornas de corte EV1. Arquivo Brasileiro de Medicina Veterinária e Zootecnia, v.59, n.3, p.797-804, 2007b. 
CORRÊA, A.B. Desempenho e características de carcaça de codornas de corte em função da idade da matriz, peso do ovo e nível nutricional. 2010.118f. Tese

(Doutorado) - Universidade Federal de Minas Gerais, Belo Horizonte.

DRUMOND, E.S.C. Avaliação de carcaça de codornas de corte alimentadas com diferentes níveis de proteína e energia. 2010. 27p. Trabalho de Conclusão de Curso (Graduação em Zootecnia) Universidade Federal dos Vales do Jequitinhonha e Mucuri, Diamantina.

LIMA, H.J.D.; BARRETO, S.L.T.; MELO, D.S.; RIBAS, N.S. Diferentes pesos corporais ao final da fase de recria sobre o desempenho produtivo de codornas japonesas. Enciclopédia Biosfera, v.7, p.404-409, 2011.

MÓRI, C.; GARCIA, E.A.; PAVAN, A.C.; PICCININ, A.; PIZZOLANTE, C.C. Desempenho e Rendimento de Carcaça de Quatro Grupos Genéticos de Codornas para Produção de Carne.

Revista Brasileira de Zootecnia, v.34, n.3, p.870-876, 2005.

NATIONAL RESEARCH COUNCIL NRC. Nutrient requirements of poultry. Washington, D.C.: National Academic Press, 1994. p.44-45.

OLIVEIRA, E.G.; ALMEIDA, M.I.M.; MENDES, A.A.; VEIGA, N.; DIAS, K. Desempenho produtivo de codornas de ambos os sexos para corte alimentadas com dietas com quatro níveis proteicos. Archives of Veterinary Science, v.7, n.2, p.75-80, 2002.
OLIVEIRA, E.G; ALMEIDA, M.I.M; MENDES, A.A. VEIGA, N.; ROÇA, R.O.; DIAS. K. Avaliação do rendimento de carcaça de codornas para corte alimentadas com dietas com diferentes níveis proteicos. Archives of Veterinary Science, v.10, n.3, p.42-45, 2005.

OTUTUMI, L.K.; FURLAN, A.C.; MARTINS, E.N.; GARCIA, E.R.M.; TON, A.P.S.; MONTEIRO, A.C. Efeito do probiótico sobre o desempenho, rendimento de carcaça e exigências nutricionais de proteína bruta de codornas de corte. Revista Brasileira de Zootecnia, v.38, n.2, p.299-306, 2009.

REZENDE, M.J.M.; FLAUZINA, L.P.; PIMENTEL, C.M.M.; OLIVEIRA, L.Q.M. Desempenho produtivo e biometria das vísceras de codornas francesas alimentadas com diferentes níveis de energia metabolizável e proteína bruta. Acta

Scientiarum.Animal Sciences,v.26, n.3, p.353-358, 2004.

ROSTAGNO, H.S.; ALBINO, L.F.T.; DONZELE, J.L.; GOMES, P.C.; OLIVEIRA, R.F.M.; LOPES, D.C.; FERREIRA, A.S.; BARRETO, S.L.T. Tabelas brasileiras para aves $\mathrm{e}$ suinos: composição de alimentos e exigências nutricionais. 2.ed. Viçosa: Universidade Federal de Viçosa, 2005. 252p.

SAS Institute. SAS/STAT® user's guide. version 6. 4.ed. Cary, NC, 1990.

SILVA, E.L.; SILVA, J.H.V.; JORDÃO FILHO, J.; RIBEIRO, M.L.G. Efeito do plano de nutrição sobre o rendimento de carcaça de codornas tipo carne. Ciência e Agrotecnologia, v.31, n.2, p.514-522, 2007. 
Rev. Bras. Saúde Prod. Anim., Salvador, v.15, n.4, p.1017-1026 out./dez., 2014 http://www.rbspa.ufba.br ISSN 15199940

TON, A.P.S; FURLAN, A.C;

MARTINS, E.N.; TOLEDO, J.B.;

SCHERER, C.; CONTI, A.C.M.

Exigências de lisina digestível e de energia metabolizável para codornas de corte em crescimento. Revista

Brasileira de Zootecnia, v.40, n.3, p.593-601, 2011.

WINTER, E.M.W. Estimação de parâmetros genéticos de características de desempenho, carcaça e composição corporal de codornas para corte (Coturnix sp.). 2005. 91f. Dissertação (mestrado) Universidade Federal do Paraná, Curitiba.

Data de recebimento: 19/12/2013

Data de aprovação: 10/11/2014 